\title{
Establishing the Basic Indicator for the Calculation of the Flood Vulnerability Index for River Basins in Vietnam
}

\author{
Can Thu Van ${ }^{1}$, Nguyen Thanh Son ${ }^{2}$ and Phan Vu Hoang Phuong ${ }^{3}$ \\ 1. Hydrology Department, Faculty of Hydro-Meteorology, Hochiminh City University of Natural Resources and Environment, \\ Hochiminh City 70000, Vietnam \\ 2. Faculty of Hydro-meteorology \& Oceanography, Hanoi University of Science, Hanoi 100000, Vietnam \\ 3. Climate Change Department, Faculty of Hydro-Meteorology, Hochiminh City University of Natural Resources and Environment, \\ Hochiminh City 70000, Vietnam
}

\begin{abstract}
Along with the concept, the method of assessing the vulnerability is becoming more and more diversified in many directions and fields. In general, these methods can be classified into two groups: (i) direct-qualitative (survey methods, integrated map ...) and (ii) indirectly-quantitative (method index). The set of indicator plays a very important role in the successful application to any method and brings reliable results. Each basin or area with different natural geography, economics and society and so on, requires a different set of indicator. However, assessing any river basin in Vietnam needs the basic indicator. This study will establish the basic indicator for the construction of flood vulnerability index in Vietnam.
\end{abstract}

Key words: Vulnerability, flood, indicator.

\section{General Concepts}

In recent years, scientists have been more interested in the concept of vulnerability especially in the areas planning to manage and mitigate the flood disaster. This aims to increase the resilience of the society by increasing resistance of the vulnerable elements [1].

Many vulnerable concepts used before can be divided into three groups [1]: (i) concepts focusing on the exposure to the catastrophes including distribution of disasters or catastrophe areas where people are living, and also the extent of damage and analysis of specific impacts [2, 3]; (ii) comcepts focusing on the social aspects and related to lesions dealing with the negative impacts from the community, including resilience and self-healing capabilities for catastrophe; (iii) a combination of both methods, determining the vulnerability as hazards which contains catastrophes as well as the impact of social adaptation.

Corresponding author: Can Thu Van, Ph.D., main research field: hydrology.
In terms of natural catastrophes, the different conceptions not only develop over time, but also develop in approaching methods. According to Fuchs et al. [4], the natural catastrophes are considered harmful factors of physical environment or the relationship between humans and nature. Modern approaches considered catastrophes as physical phenomena affecting the life and habitats of humans [3], which were defined as the frequency of the potential damaging phenomena [2].

The vulnerable components, closely related to natural disasters, are used to manage catastrophes in many different vulnerable ways, such as structural engineering, infrastructure, communications systems, economic and social [5]. There are two points of view in the vulnerability, social science perspective and natural science perspective (technical).

Aiming to minimize the harm caused by natural disasters in the context of climate change, Intergovernmental Panel on Climate Change (IPCC) has researched and developed the definitions of 
vulnerability on climate change and the rise of sea level for years. Initially, "vulnerability was the extent to which climate change may damage or be disadvantage to the system; at that time, it does not only depend on the sensitivity of the system, but also depends on the ability of communities to adapt to new climate conditions". This definition includes the components that are exposure, sensitivity and resilience of the system against the natural disasters. In general, studies assessing the vulnerability previously focused largely on assessment of physical agents but less considered the state of the social system and the community.

\section{Method of Determining the Vulnerability Flood Index}

To assess the vulnerability of all 3 factors studied (exposure, sensitivity and capacity), "in terms of exposing to stress or crisis, vulnerability is not only caused by exposing to dangers but also depends on the ability to cope with the affected people". The ability of people to deal with them is regarded as a combination of resistance and resilience after disasters. This means researching the vulnerability of flood is the consideration and selection of the elements of exposure, sensitivity, and the ability of people, ensuring that it would match typical characteristics of each region or basin. Analyzing vulnerability index helps managers have a comprehensive view on the sensitivity or capacity of the affected people and even the economic-society system in the studied area. This study will be directed to the vulnerability of natural, social, economic and environmental factors, which are the indicators of exposure, sensitivity and resilience of the community against flood catastrophes.

With the development of the IPCC [6] on climate change vulnerability, the definition of vulnerability due to floods can be stated as: "Vulnerability is the degree to which geophysical, biological and socio-economic systems are susceptible to and unable to cope with, adverse impacts of flooding, as determined through risk indicator, exposure, sensitivity and capacity".
Vulnerability index is considered to be a function of the vulnerability flood index, exposure, sensitivity and capacity of Eq. (1):

$V=f(H, E, S, A)$ in which $\mathrm{V}$ is the vulnerability flood index; $\mathrm{H}$-flooding magnitude; $\mathrm{E}$ - exposure; S-sensitivity and A—capacity. Specifically:

$$
V_{j}=H_{j}{ }^{*} w_{H}+E_{j}{ }^{*} w_{E}+S_{j}{ }^{*} w_{S}-A_{j}{ }^{*} w_{A}
$$

in which $V_{J}$-vulnerability flood index nodal point $\mathrm{j}$; $H_{J}$-flood magnitude indicator value; $E_{J}$-exposure indicator value; $S_{J}$-sensitivity indicator value; $A j$ - capacity indicator value; $w_{H}, w_{E}, w_{S}, w_{A}$ : weight of the 4 indicators (total weight value $=1$ ).

Establish the Indicator for Calculation of the Vulnerability Flood Index:

- Flood magnitude $-\mathrm{H}$ is interpreted as a direct threat, involving the nature and extent of floods: depth, duration and flow velocity:

Simulated results used hydrological and hydraulic model, in this study the use of 1, 2 directions hydraulic model for simulating flood events such as the characteristics mentioned for each calculation cell.

- Exposure-E is the nature and extent of the system's exposure to flood event, as shown by the type of land use. An indicator value of exposure is determined by the value of the variable land use;

Data is collected from maps of land use for each calculation cell. If a cell contains a variety of lands, weighted average (area) will be calculated.

- Sensitivity-S is an expression of the social system through the activities of human life against flood catastrophe, including 4 components: people, livelihoods, infrastructure and the environment;

- Capacity-A is the reaction of the basin to flood hazards to limit the vulnerability by floods, including 4 components: conditions, experience, support and resilience.

Sensitivity and Capacity were collected mainly from household questionnaires, commune questionnaires, and District Statistical Yearbook. This questionnaire was designed with indicator corresponding to each answer of the audiences' questions. 
On the basis of establishing indicator for assessing the vulnerability by floods, this study proposed a set of indicators includes 43 variables, which are: flood risk-3 variables, exposure-1 variable, sensitivity -23 variables, resilience -16 variables as in Table 1.

When the values of the indicators are set, vulnerability index will be calculated after being normalized and weight determined (shown in other publications), vulnerability of floods will be assessed and flood management methods will be proposed on the basis of calculated vulnerability index.

\section{Case study}

Calculation methods were shown in details in Refs. $[1,6]$.

Table 1 List of indicators.

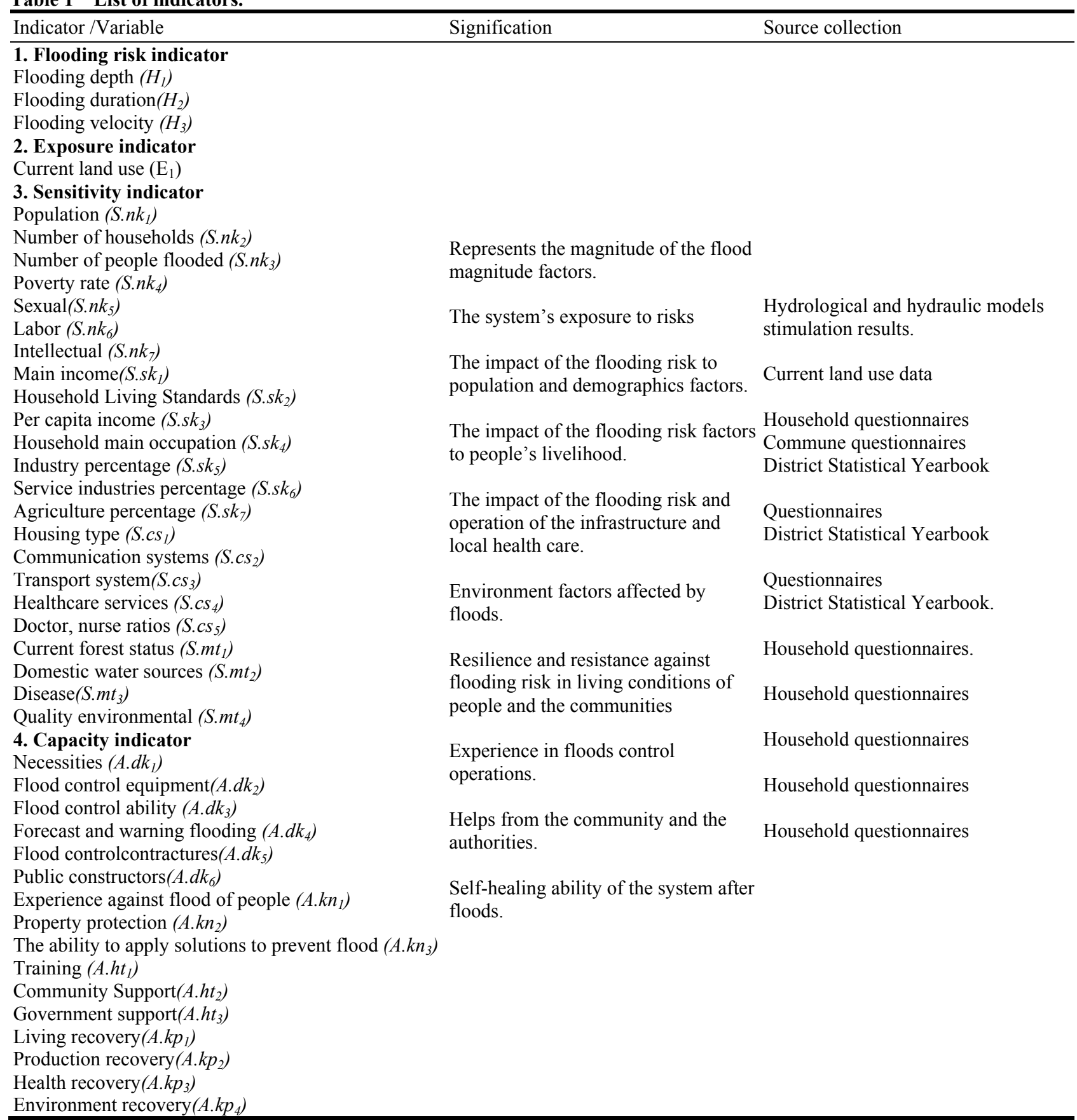




\subsection{Results Calculated in Da Nang City}

Table 2 shows that Hoa Tho Commune (Hoa Vang District) and Hoa Cuong (Hai Chau District) have the highest vulnerability index (0.36 to 0.42 ), whereas the communes such as Thanh Binh (Hai Chau), Bac My An (Marble Mountains) and Khue Trung (Son Tra) have the lowest vulnerability index (0.22 to 0.25$)$. Communes with lower vulnerability index are largely due to lower $\mathrm{H}$ index. On the other hand, communes with vulnerability index above $\mathrm{H}$ also have a high sensitivity value (S). Based on analysis of the indicators that form the vulnerability index, people could develop the most suitable options for each locality in order to minimize the risk of flooding in Da Nang.

\subsection{Results Calculated in An Giang Province}

With the same indicators, this study calculated the Mekong upstream floods flowing through An Giang Province and figured out that vulnerability index was as high as in Tinh Bien and Thoai Son due to low resistance and high flooding risk. By contrast, Chau Doc City had high flooding risk but low sensitivity so its vulnerability index was at average level. Finally, Long Xuyen City had the lowest vulnerability level in An Giang Province due to the lowest flooding risk and high ability to cope with floods. Both locations and calculations showed that the local's extent of damage is quite similar to the calculation results whenever there are catastrophes.

Table 2 Calculation result vulnerability indicator by floods in Da Nang city.

\begin{tabular}{|c|c|c|c|c|c|c|c|}
\hline No. & Ward & Districts & $\mathrm{H}$ & E & $\mathrm{S}$ & A & VFI \\
\hline 1 & Hoa Tho & Hoa Vang & 0.11 & 0.45 & 0.67 & 0.35 & 0.42 \\
\hline 2 & Binh Hien & Hai Chau & 0.09 & 0.58 & 0.35 & 0.32 & 0.28 \\
\hline 3 & Binh Thuan & Hai Chau & 0.09 & 0.51 & 0.35 & 0.30 & 0.27 \\
\hline 4 & Hoa Cuong & Hai Chau & 0.18 & 0.62 & 0.46 & 0.31 & 0.36 \\
\hline 5 & Hoa Thuan & Hai Chau & 0.06 & 0.77 & 0.46 & 0.32 & 0.34 \\
\hline 6 & Hai Chau & Hai Chau & 0.11 & 0.81 & 0.31 & 0.31 & 0.30 \\
\hline 7 & Hai Chau II & Hai Chau & 0.00 & 0.83 & 0.31 & 0.30 & 0.26 \\
\hline 8 & Khue Trung & Hai Chau & 0.13 & 0.78 & 0.33 & 0.31 & 0.31 \\
\hline 9 & Nam Duong & Hai Chau & 0.00 & 0.86 & 0.33 & 0.33 & 0.28 \\
\hline 10 & Phuoc Ninh & Hai Chau & 0.10 & 0.64 & 0.33 & 0.31 & 0.28 \\
\hline 11 & Thach Thang & Hai Chau & 0.12 & 0.76 & 0.33 & 0.31 & 0.30 \\
\hline 12 & Thanh Binh & Hai Chau & 0.00 & 0.38 & 0.33 & 0.30 & 0.22 \\
\hline 13 & Thuan Phuoc & Hai Chau & 0.12 & 0.31 & 0.32 & 0.31 & 0.25 \\
\hline 14 & Ноа Hai & Ngu Hanh Son & 0.21 & 0.28 & 0.35 & 0.31 & 0.29 \\
\hline 15 & Hoa Bac & Ngu Hanh Son & 0.00 & 0.70 & 0.47 & 0.33 & 0.32 \\
\hline 16 & Bac My An & Ngu Hanh Son & 0.00 & 0.34 & 0.34 & 0.34 & 0.23 \\
\hline 17 & An Hai Dong & Son Tra & 0.00 & 0.87 & 0.47 & 0.33 & 0.34 \\
\hline 18 & An Hai Tay & Son Tra & 0.19 & 0.27 & 0.34 & 0.31 & 0.28 \\
\hline 19 & Hoa Hiep & Son Tra & 0.07 & 0.00 & 0.46 & 0.34 & 0.27 \\
\hline 20 & Hai Bac & Son Tra & 0.09 & 0.53 & 0.46 & 0.31 & 0.32 \\
\hline 21 & Hai Chau & Son Tra & 0.00 & 0.88 & 0.31 & 0.30 & 0.27 \\
\hline 22 & Khue Trung & Son Tra & 0.02 & 0.21 & 0.35 & 0.30 & 0.22 \\
\hline 23 & Nai Hien Dong & Son Tra & 0.12 & 0.35 & 0.31 & 0.30 & 0.25 \\
\hline 24 & Phuoc My & Son Tra & 0.02 & 0.78 & 0.33 & 0.32 & 0.27 \\
\hline 25 & An Khe & Thanh Khe & 0.00 & 0.82 & 0.35 & 0.34 & 0.28 \\
\hline 26 & Chinh Gian & Thanh Khe & 0.00 & 0.85 & 0.32 & 0.34 & 0.27 \\
\hline 27 & Ton Tranh & Thanh Khe & 0.00 & 0.82 & 0.35 & 0.33 & 0.28 \\
\hline 28 & Thach Gian & Thanh Khe & 0.00 & 0.79 & 0.46 & 0.35 & 0.33 \\
\hline 29 & Thanh Loc & Thanh Khe & 0.00 & 0.64 & 0.31 & 0.34 & 0.25 \\
\hline 30 & Vinh Trung & Thanh Khe & 0.00 & 0.77 & 0.46 & 0.34 & 0.32 \\
\hline 31 & Xuan Hoa & Thanh Khe & 0.00 & 0.53 & 0.35 & 0.34 & 0.25 \\
\hline
\end{tabular}




\section{Conclusion}

This research has proposed a set of indicators to assess the level of damage caused by floods to the affected localities where floods have different characteristics. It shows that the ability to use the indicator for intensive access to serve the prevention and mitigation of natural disasters effectively with scientific basis. However, for good results, the indicators also need to be studied at particular regions as well as apply the most suitable calculation method (weight, general indicators calculation formula indicators).

\section{Acknowledgement}

This article is done within the framework of the ministerial-level research project (MONRE), code TNMT2016.05.15. and research project National University Hanoi QG16-15. The authors wish to thank them.

\section{References}

[1] Son, N. T., and Van, C. T. 2014. "Part 3: Calculation of the Vulnerability Index due to Floods by Weighting Method-Testing on Communal Units in Thu Bon River Basin." Vietnam National University Journal of Science and Technology 30 (4S): 150-158.

[2] Alexander, D. 1991. "Natural Disasters: A Framework for Research and Teaching Disaster." Disaster 15 (3): 209-226.

[3] Heyman, B. N., Davis, C., and Krumpe, P. F. 1991. "An Assessment of Worldwide Disaster Vulnerability." Disaster Management 4: 3-36.

[4] Fuchs, S., Heiss, K., and Hübl, J. 2007. "Towards an Empirical Vulnerability Function for Use in Debris Flow Risk Assessment." Nat. Hazards Earth Syst. Sci. 7: 495-506.

[5] IPCC. Climate Change 2001: Impacts, Adaptation and Vulnerability. Cambridge: Cambridge University Press.

[6] Van, C. T. 2015. "Study to Establish the Scientific Basis for Assessment of Serving Vulnerable Flood Prevention in Vu Gia-Thu Bon.” Ph.D. thesis. Vietnam NationalUniversity, Hanoi. 